\title{
Coffee biowaste valorization within circular economy: an evaluation method of spent coffee grounds potentials for mortar production
}

\author{
Giada La Scalia $^{1}\left(\right.$ Manfredi Saeli $^{2} \cdot$ Pier Paolo Miglietta $^{3} \cdot$ Rosa Micale $^{1}$
}

Received: 1 June 2021 / Accepted: 20 August 2021 / Published online: 19 September 2021

(c) The Author(s) 2021

\begin{abstract}
Purpose Spent coffee grounds (SCG) are biowastes extensively generated within the coffee supply chain. Nowadays, their disposal represents an increasing environmental concern due to its toxicity and organic nature. With the estimated increase of coffee production and consumption in the upcoming years, there is an imperative need to find a proper reverse option, along with a novel industrial application, which allows for the valorization of this coffee by-product within a circular economy perspective. This study aims at investigating a potential reuse of spent coffee grounds to produce novel construction materials to be used for sustainable buildings.

Methods After having illustrated the forward flows within the coffee life cycle and the potential reverse flow options, an evaluation method based on multi-criteria analyses was elaborated to test not only the technical but also the environmental and economic performances of novel materials originating from the incorporation of SCG as an aggregate in natural hydraulic lime and geopolymer-based mortars. Moreover, we focus on the reuse of another waste streams — biomass fly ash — deriving from the paper-pulp industry, rarely investigated in both traditional construction applications and in geopolymer manufacture. The two (geopolymer- and lime-based) mortar typologies are here studied and compared as potential green material for applications in construction, with satisfying engineering performance and high insulation attitude, giving a new life to a common organic waste. Consequently, we compare eight formulations by means of multi-criteria approaches that are nowadays claimed as a useful and effective decision aiding support instrument to assess the development of new sustainable construction materials. They permit to consider simultaneously some controversial and often uncertain aspects like technological (as the usual scientific studies do), environmental, and economic (more difficult to easily approach and evaluate). For this purpose, in this paper, we have analyzed the performance of the novel bio-composite mortars using VIKOR and TOPSIS methods to rank a set of alternatives according to various evaluation criteria that often conflict one with each other. Results Results show that adding spent coffee grounds can efficiently improve the technical and sustainable performances of the novel mortars for different applications in the building sector. The presence of SCG increases water absorption and improves the insulation performance along with an environmental impact reduction. The considered technological properties are highly promising — such as the improvement in thermal insulation. In particular, even the addition of only 5\% SCG leads to a significant reduction of the thermal conductivity and consequently to a greater insulating performance.

Conclusions To date, most of the available literature on recycling SCG in construction materials do not consider mortarbased applications and, moreover, nor multi-criteria approaches. Therefore, our study proposes itself as an innovative track solution to food waste management lowering the employment of non-renewable natural resources and the costs associated to construction material production. At the same time, a novel and innovative way of such waste disposal is suggested, pursuing the sustainability and substantially reducing the environmental impact of construction and building materials. This study is a fundamental step in assessing the applicability of our designed and produced materials and its potentials to be produced at an industrial scale.
\end{abstract}

Keywords Coffee supply chain · Life cycle approach · Food waste valorization · Circular economy · Construction material · Multi-criteria analysis · Sustainability

Communicated by Giovanni Mondello.

Extended author information available on the last page of the article 


\section{Introduction}

Coffee is one of the most consumed and popular beverages drunk worldwide. Despite social distancing, required by the COVID-19 pandemic spreading, is limiting de facto the common out-of-home coffee consumption and the global economy recover, the consumption of coffeebased beverages during 2021 is estimated to increase by $1.3 \%$, amounting to about 166 million bags (9978 million $\mathrm{kg}$ ) (ICO 2021). Nevertheless, the coffee industry is globally responsible for producing a great quantity of waste, mainly "coffee silver skin" and spent coffee grounds (SCGs) (Mussatto et al. 2011; Murthy 2012). The latter are mainly generated from the brewing process or by the soluble coffee industry. It is reported that approximately 6 million tons of SCGs are produced every year worldwide (Getachew and Chun 2017). The traditional disposal procedure of this residue is in landfill; however its dispersion into the environment should be strongly prevented due to its potential toxicity and organic nature (Ktori et al. 2018; Massaro Sousa and Ferreira 2019). Indeed, disposing SCGs in landfills is unsafe, as for most organic wastes, because the risk of spontaneous combustion is quite high, and, moreover, an excessive production of harmful methane and carbon dioxide may occur (Massaro Sousa and Ferreira 2019) contributing to the overall atmospheric pollution.

In this context, various industries decided to change their development model, focusing on the use of sustainable as well as renewable, eco-friendly, and cheap resources, like SCGs, adopting a circular economy approach (Karmee 2018; Son et al. 2018; Nguyen et al. 2019; Dattatraya Saratale et al. 2020).

Worldwide, there has been growing attention and interest among researchers and industries to utilize re-usable resources aimed at generating more sustainable materials to be applied in construction. Many studies are focused on developing sustainable construction and building materials, especially as an alternative to the Portland cement claimed to be one of the most polluting industries in the sector (Saberian et al. 2021).

Agri-food by-products and biowaste reuse shows great potentialities in the construction industry. As shown by much of the literature, life cycle methodologies underpin Circular Economy strategies but also highlight some weaknesses (Notarnicola et al. 2016; Peña et al. 2021) which can be overcome through the proper use of multi-criteria approaches. Recent studies, in fact, have demonstrated that multi-criteria approaches are a useful and effective decision aiding support tools to assess the potentials of new sustainable construction materials (Moretti et al. 2017; Kurda et al. 2019; Saeli et al. 2020). In the selection of novel materials, the need to consider simultaneously contradictory and often uncertain aspects-like technological, environmental, and economic ones-makes the multicriteria approach extremely suitable (Micale et al. 2017), even if to date, most of the available literature on recycling SCG in construction materials has not considered in multicriteria approaches (Saberian et al. 2021).

This study aimed at examining the performance of novel mortars obtained by incorporating various amounts of SCG as aggregate in substitution (volume \%) to the traditional sand. For this purpose, two different typologies of binder were considered: a green geopolymer that employs itself an industrial waste as raw material, biomass fly ash (BFA), and a traditional hydraulic lime. The application of multicriteria approach is proposed to provide further knowledge on the development of an alternative SCG recycle option to ordinary disposal in landfill, the potentials of the sustainable construction materials based on SCG reuse. In order to evaluate the industrial feasibility of the proposed solution from environmental and economic perspectives, the VIKOR (VIekriterijumsko KOmpromisno Rangiranje) (Opricovic 1998) and the TOPSIS (Technique for Order of Preference by Similarity to Ideal Solution) (Hwang and Yoon 1981) multi criteria decision-making methods were implemented to rank a set of alternatives according to various evaluation criteria often conflicting with one another (Opricovic and Tzeng, 2004; Chu et al. 2004; Opricovic and Tzeng 2007; La Fata et al. 2021).

In the light of the circular economy (CE) approach, the coffee biowaste valorization presented in this study is at a preliminary stage. Consequently, future studies should focus on the techno-economic analysis along with the industrial scale productivity and the producible bioproduct feasibility.

The remainder of this paper is organized as follows. Section 2 presents the coffee life cycle and its circular economy potentials. Section 3 outlines the study methodological approach, providing also an overview of the evaluation criteria. Section 4 presents the case study and discusses the findings, before the study is concluded in Sect. 5 .

\section{Coffee life cycle and circular economy}

Coffee is nowadays considered one of the most appreciated beverages internationally. It is grown in over 70 countries, and it immediately follows petroleum as the second most globally traded commodity (Crossley et al. 2020).

Cultivated mainly in tropical climates, the coffee life cycle begins with freshly picked coffee cherries (Fig. 1). As described by Murthy and Naidu (2012) and Figueroa et al. (2016), coffee beans are then processed through (i) the dry process which uses sunlight to simply dry the 


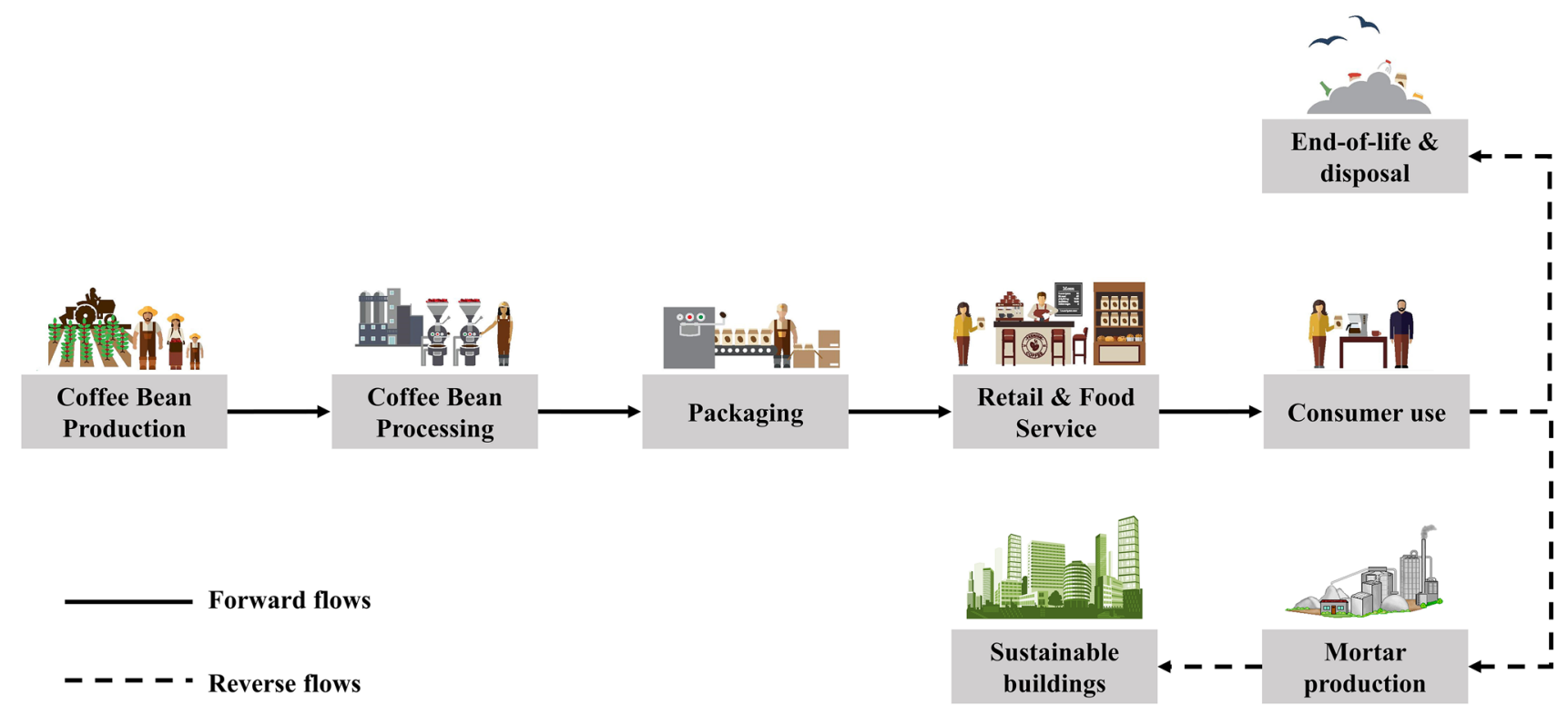

Fig. 1 Forward and reverse flows within the coffee life cycle

cherry, allowing the "coffee bean" to be removed, and/ or (ii) the more complex wet process, based on the use of water and pressure, which allows the coffee pulp to be removed, obtaining clean coffee beans, but also highly polluted wastewater.

After either process is completed, the beans are roasted, which subsequently results in the bean shedding its thick protective coating or "coffee silver skin." Finally, the beans are packaged and distributed to retail and food services, cafes, and households where the beans are ground and brewed, resulting in the production of the final SCG biowaste (Fig. 1).

Fifty percent of the coffee beverage impacts refers to the life cycle stages under the control of producers and their suppliers (coffee bean production, processing, packaging, and distribution) and the other $50 \%$ under the control of users (retail and food services, consumers, and final disposal) (de Figueiredo Tavares and Mourad 2020).

The forward flows within the whole coffee life cycle, from coffee cherry to coffee grounds, have gained more spread over time resulting in more production and subsequently more damage. However, although the entire lifetime of the coffee supply chain produces, each year, a large amount of biowaste (Kovalcik et al. 2018) whose value is widely discussed in the literature (Musatto et al. 2011; Acevedo et al. 2013; Luz et al. 2018; Franca and Oliveira 2019; Schmidt Rivera et al. 2020), SCGs certainly represent the largest percentage.

Since the global demand for coffee-based beverages constantly increases, subsequently SCGs will also continue to grow, proving detrimental to the environment. SCG physical properties and chemical compositions are thus fundamental in exploring their potential to be used within a circular economy context (Rangarajan 2019).

Apart from the more established SCG recycling applications in various industrial sectors, especially that of soil conditioner, compost, and fertilizers and that of biobased additives (e.g., Ronga et al. 2016; Santos et al. 2017; Najdanovic-Visak et al. 2017; Girotto et al. 2018), attentions have been concentrated on the opportunity to avoid end-oflife and disposal of SCGs, proposing an alternative potential reverse flow (Fig. 1) within the coffee supply chain aimed at using SCGs in the production of construction material for sustainable buildings and civil engineering applications.

In fact, the main purposes of the current study are (i) to investigate the SCG incorporation as an aggregate in construction materials, allowing for the valorization of coffee biowaste within a circular economy approach, and (ii) to develop an evaluation method of SCG potential for mortar production also based on the life cycle approach towards sustainable buildings.

\section{Material and methods}

\subsection{Spent coffee grounds}

The SCGs used in this study were illustrated in Fig. 2 and obtained as a domestic waste deriving from the ordinary moka Italian coffee makers, and-prior to use-it was dried naturally until the material had almost no moisture content. The used SCG particle size distribution was 


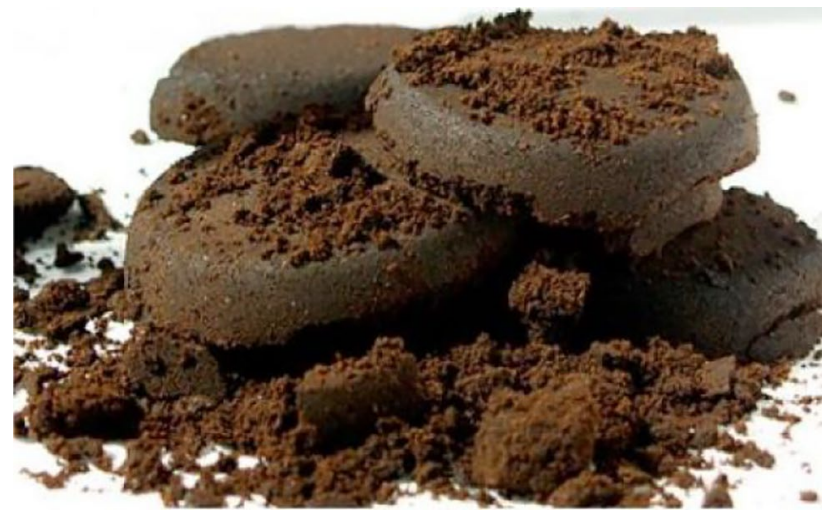

Fig. 2 Spent coffee grounds

measured by laser diffraction (Coulter LS230 analyzer, Fraunhofer method and Polarization Intensity Differential Scattering) and the median particle dimension resulted $243.7 \mu \mathrm{m}$. Based on the Brunauer-Emmett-Teller analysis (BET), the SCG surface area resulted to be $0.48 \mathrm{~m}^{2} / \mathrm{g}$. The bulk density of the dried particle was $400 \mathrm{~kg} / \mathrm{m}^{3}$, and, compared with the density of lightweight aggregates, SCGs might be exploited in lightweight concrete production with unit weight less than $1900 \mathrm{~kg} / \mathrm{m}^{3}$ (ACI 213 2003). In Fig. 3 the micro-morphological features (SEM) of SCGs are shown; the image reveals a corrugated surface with jagged and crumpled particles, but a compact matrix.

\subsection{Mortar specimens}

In this study, mortars employing two different typologies of hydraulic binder-geopolymer (GP) and natural hydraulic lime (NHL) - and manufactured with various quantities of SCG were considered and compared.

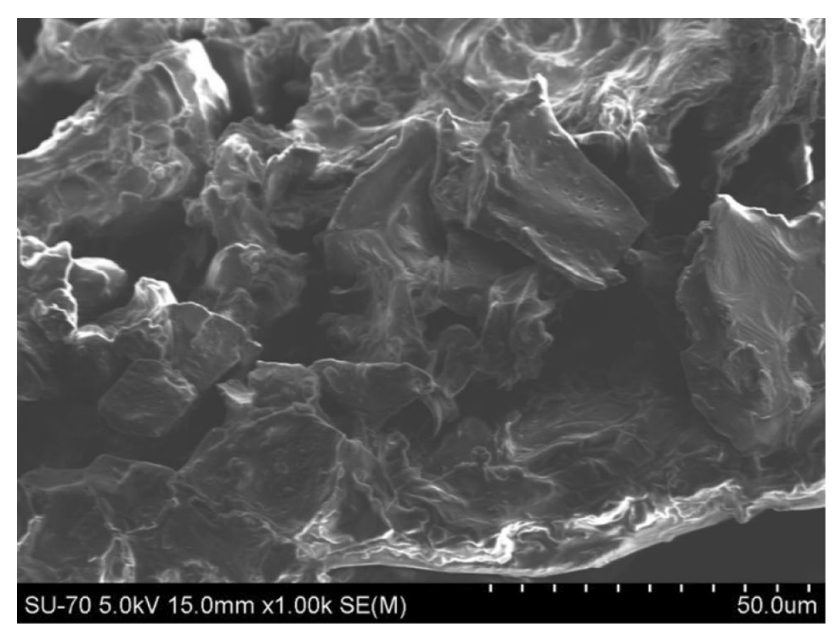

Fig. 3 Micrograph image of SCG
The first mortar typology was prepared from an innovative GP binder designed and manufactured according to previous studies of authors (Saeli et al. 2017, 2019a, 2019b). GP is a hydraulic alkali-activated binder usually investigated as a possible greener substitute to Ordinary Portland Cement. In this study, the formulation used foresees a mixture of BFA and metakaolin (MK) as a solid source of alumina and silica, in a ratio BFA/MK equal to 70:30 wt.\%. The BFA used is a solid waste deriving from the paper-pulp industrial Kraft process. It is important to highlight that in this study the BFA largely substituted the MK as a source of alumina and silicate, improving the material's sustainability. It is obtained by reusing a waste product, saving natural resources (kaolin used to prepare the MK), eliminating the carbon footprint associated with MK manufacturing (extraction, transport, calcination, etc.), minimizing the financial commitment for waste disposal, etc. The alkaline activator was prepared mixing sodium silicate and sodium hydroxide as in Saeli (2019a). Details of the raw materials used and GP binder characterization are presented in the mentioned references. The second mortar typology was prepared from NHL as a binder, produced by Axton and furnished in powder. In this study, NHL is used as reference being a traditional commonly used material in construction.

The used aggregate consisted in a mixture of a natural siliceous sand (particle dimension ranging $0-4 \mathrm{~mm}$ ) and SCG. The aggregate mix design is shown in Table 2. For both the considered mortars (NHL-based and GP-based), the selected binder/aggregate ratio was constant and equal to $1: 3$ in volume. Virgin NHL-mortar (NHL_0, without SCG) was designed in order to present the same workability (spread) of the reference GP-mortar (GP_0, without SCG) (cfr. Table 1). That resulted for a water/NHL ratio equal to 1:1. Consequently, the resulting mortars' water/solid ratios resulted 0.155 and 0.196 for NHL-mortar and GP-mortar, respectively.

The relevant features of the reference NHL-mortar and GP-mortar are summarized in Table 1.

In this study, the main properties and performance of the NHL-mortars and GP mortars manufactured implementing the SCG waste quantities were analyzed, compared, and

Table 1 Main characteristics of the used reference mortars

\begin{tabular}{lll}
\hline Property & \multicolumn{2}{l}{ Measured value } \\
\cline { 2 - 3 } & NHL-mortar & GP-mortar \\
\hline Workability (spread by flow table) $[\mathrm{cm}]$ & 21 & 21 \\
Water/solid ratio & 0.155 & 0.196 \\
Bulk density [Kg/m $\left.{ }^{3}\right]$ & 1706 & 1832 \\
Water absorption $[\%]$ & 11 & 13 \\
Compressive strength [MPa] & $14.10 \pm 0.18$ & $21.66 \pm 1,91$ \\
Flexural strength [MPa] & $2.76 \pm 0.016$ & $4.08 \pm 0.72$ \\
\hline
\end{tabular}


Table 2 Mortar formulations: aggregate mix design

\begin{tabular}{|c|c|c|c|c|c|c|}
\hline \multirow[t]{3}{*}{$\mathrm{N}$} & \multirow[t]{3}{*}{ ID } & \multirow[t]{3}{*}{ Substitution [volume \%] } & \multicolumn{4}{|c|}{ Mix design-aggregate } \\
\hline & & & \multicolumn{2}{|c|}{ Volume [\%] } & \multicolumn{2}{|c|}{ Volumetric part } \\
\hline & & & Sand & Coffee & Sand & Coffee \\
\hline 1 & NHL_0 & 0 & 100 & 0 & 3 & 0 \\
\hline 2 & NHL_5 & 5 & 95 & 5 & 2.85 & 0.15 \\
\hline 3 & NHL_10 & 10 & 90 & 10 & 2.7 & 0.3 \\
\hline 4 & NHL_17.5 & 17.5 & 82.5 & 17.5 & 2.475 & 0.525 \\
\hline 5 & GP_0 & 0 & 100 & 0 & 3 & 0 \\
\hline 6 & GP_5 & 5 & 95 & 5 & 2.85 & 0.15 \\
\hline 7 & GP_10 & 10 & 90 & 10 & 2.7 & 0.3 \\
\hline 8 & GP_17.5 & 17.5 & 82.5 & 17.5 & 2.475 & 0.525 \\
\hline
\end{tabular}

ranked by using multi-criteria decision-making methodologies. The foreseen use is a plastering application for novel architectural finishing with insulating performance. Mortar mix design was formulated in order to improve the material performance, along with its sustainability, by adding increasing quantities of SCG to substitute the sand. More particularly, the aggregate was prepared by substituting increasing quantities of sand with SCG $(5 \%, 10 \%, 17.5 \%$ in volume) until the material became too viscous to be appropriately mixed (cfr. flow table test). Eight different formulations were considered as listed in Table 2 . Here, the aggregate mix design is presented in volumetric parts extrapolated from the whole mortars mix designs (binder-GP or NHL_-and liquid, water or alkaline activator, parts are not shown as the two products derive from different manufacturing processes). Also, the relative volume percentages among sand and SCG are shown.

The testing specimens were produced in accordance with EN 998-2: 2016 and UNI EN 196:1: 2016. In the case of the GP-mortar, the procedure was derived from the common method for traditional cementitious materials. The manufacture process is simple and reproducible and was performed at environmental conditions $\left(25^{\circ} \mathrm{C}, 65 \% \mathrm{RH}\right)$, avoiding external fonts of heat, as frequently done in GP-manufacturing, making the material more sustainable. The first step of the manufacturing process foresees the precursors' preparation: the solid alumino-silicate source $(\mathrm{BFA}+\mathrm{MK})$ and the liquid alkaline activator. Precursors are mixed for 9 min to produce the GP binder. Then, the aggregate (sand, eventually admixed with the SCG waste) is added to the slurry and mixed for $1 \mathrm{~min}$ to ensure uniformity. At this stage the mortar is produced. The slurry was then poured in standard metallic molds (UNI EN 1015-11:2007), vibrated for 2 min, sealed until hardening (1 day). Samples were then cured until testing (28th day), in accordance with the standardized testing procedure. NHL-mortar was produced mixing the lime with water for $30 \mathrm{~s}$. Here, the used water was taken from the municipal aqueduct in accordance with UNI EN
1008:2003 and UNI EN 206-1: 2006. Subsequently the aggregate (sand or sand + SCG) was added and mixed for other $210 \mathrm{~s}$ (total mixing time was $240 \mathrm{~s}$ ). The slurry was then poured into the same standard metallic molds, vibrated for $2 \mathrm{~min}$, sealed for 7 days ( 2 days in the mold and 5 days demolded), in accordance with the relevant standard; specimens were then cured for other 28 days until testing (Boresi et al. 1993).

\subsection{Evaluation criteria}

With the aim of selecting the best SCG quantity to substitute the sand, different evaluation criteria have to be taken into account depending on the particular application for which they are intended (Saeli et al. 2020; Chudley 2016). This choice is related to the freshness and hardness properties of the materials (e.g., workability, bulk density, compressive strength, etc.) and the environmental and economic impacts.

The evaluation criteria selected in this study were the following:

Uniaxial compressive strength [MPa] (UCS) indicates the material resistance to compressive loads. According to EN 998-2:2016, it was measured using a universal testing machine (Shimadzu, AG-25TA), equipped with a $250 \mathrm{kN}$ load cell running at $0.5 \mathrm{~mm} / \mathrm{min}$ displacement rate. The given value is the mean from three tests.

Axial strain [\%] (AS) is the specimen strain at rupture by compression (cf. UCS) and was calculated as the quotient between the displacement at rupture and the initial specimen length.

Flexural strength [MPa] (FS) indicates the maximum resistance by pure flexion. It was determined using a universal testing machine (Shimadzu, AG-25TA), equipped with a $20 \mathrm{kN}$ load cell running at $0.5 \mathrm{~mm} / \mathrm{min}$ displacement rate. The given value is the mean calculated from three tests. 
Bending deflection $[\mathrm{mm}](\mathrm{BeD})$ represents the degree to which the simply supported specimen $(10 \mathrm{~cm}$ distance $)$ is displaced under the load applied in the center.

Bulk density $\left[\mathrm{kg} / \mathrm{m}^{3}\right](\mathrm{BuD})$ represents the geometric mean value calculated from three different specimens cured for 28 days.

Water absorption by immersion [\%] (WAI) indicates the quantity of water-by weight variation $(\Delta \mathrm{P} / \mathrm{P} \%)$ absorbed by a specimen in consequence of full immersion in water. The value is the average from three tests.

Workability $[\mathrm{cm}](\mathrm{W})$ indicates the consistency of the just produced slurry returning the product attitude to be mixed until reaching homogeneity and consequently used conveniently. It is strictly related to the slurry fluidity (or conversely viscosity) and the specific considered application. It was evaluated by flow table test in accordance with EN 1015-3:1999 and expressed in terms of spread. Thermal conductivity $[\mathrm{W} / \mathrm{m} \cdot \mathrm{K}]$ (TC) indicates the heat transfer rate through the specimens' surfaces and was measured using a calorimeter HFM-CT 1000, in accordance to ISO 6946: (2017).

Sustainability [qualitative] (S) intends the environmental and economic impact reduction in terms of waste disposal. As SCG contains many harmful compounds-such as polyphenols, tannins, and caffeine that may pollute the environment- the greater the amount of SCG used in the material, the lower the costs for its disposal and the greater raw materials saving (less the sand usage). This criterion is qualitative, and it is expressed in the range $[1 ; 10]$.

\subsection{The VIKOR method}

The traditional VIKOR method, introduced by Opricovic (1998), is a multi-criteria decision-making approach useful for dealing with complex systems (Chatterjee and Chakraborty 2016; Opricovic and Tzeng 2004). This method allows for a ranking of a set of options when the evaluation criteria are in conflict with each other and suggests a compromise solution (Opricovic and Tzeng 2007). VIKOR is built on an aggregating function that expresses the closeness to the ideal solution, and it considers the relative criteria importance and a balance between individual and total satisfaction (San Cristobal 2011). The approach needs the following input data: (i) a decision matrix $F$ where the element $f_{i j}$ represents the rating of the alternative $i(i=1, \ldots, n)$ with respect to criterion $j(j=1, \ldots, m)$ and (ii) the weights of criteria $w_{j}$.

Table 3 Criteria weights and their preference versus
The approach follows the subsequent steps:

Best and worst scores (i.e. $f_{j}^{*}$ and $f_{j}^{-}$) will be determined for every criterion $j$. In detail, for benefits criteria

$f_{j}^{*}=\max _{i} f_{i j} \quad j=1, \ldots, m$

$f_{j}^{-}=\min _{i} f_{i j} \quad j=1, \ldots, m$

whereas for costs criteria:

$f_{j}^{*}=\min _{i} f_{i j} \quad j=1, \ldots, m$

$f_{j}^{-}=\max _{i} f_{i j} \quad j=1, \ldots, m$

Calculation of $S_{i}$ and $Q_{i}$ for every alternative $i$ :

$$
\begin{gathered}
S_{i}=\sum_{j=1}^{m}\left[\frac{w_{j} \cdot\left(f_{j}^{*}-f_{i j}\right)}{\left(f_{j}^{*}-f_{j}^{-}\right)}\right] i=1, \ldots, n \\
Q_{i}=\max _{j}\left[\frac{w_{j} \cdot\left(f_{j}^{*}-f_{i j}\right)}{f_{j}^{*}-f_{j}^{-}}\right] i=1, \ldots, n
\end{gathered}
$$

Calculation of the $R_{i}$ value for every alternative $i$ :

$$
R_{i}=v \cdot \frac{\left(S_{i}-S^{*}\right)}{\left(S^{-}-S^{*}\right)}+(1-v) \cdot \frac{\left(Q_{i}-Q^{*}\right)}{\left(Q^{-}-Q^{*}\right)} \quad i=1, \ldots, n
$$

where

$$
\begin{aligned}
& S^{*}=\min _{i} S_{i} \\
& S^{-}=\max _{i} S_{i} \\
& Q^{*}=\min _{i} Q_{i} \\
& Q^{-}=\max _{i} Q_{i}
\end{aligned}
$$

and $0 \leq v \leq 1$. In particular, when $v$ is small (i.e., $v<0.5)$, the individual regret is emphasized, whereas as $v$ increases (i.e., $v>0.5$ ), the strategy of maximum group utility is favored. The value $v=0.5$ represents, instead, the 
Table 4 Decision matrix of the proposed case study

\begin{tabular}{llllllllll}
\hline & $\begin{array}{l}\text { UCS } \\
{[\mathrm{MPa}]}\end{array}$ & $\begin{array}{l}\text { AS } \\
{[\%]}\end{array}$ & $\begin{array}{l}\text { FS } \\
{[\mathrm{MPa}]}\end{array}$ & $\begin{array}{l}\text { BeD } \\
{[\mathrm{mm}]}\end{array}$ & $\begin{array}{l}\text { BuD } \\
{\left[\mathrm{kg} / \mathrm{m}^{3}\right]}\end{array}$ & $\begin{array}{l}\text { WAI } \\
{[\%]}\end{array}$ & $\begin{array}{l}\text { W } \\
{[\mathrm{cm}]}\end{array}$ & $\begin{array}{l}\text { TC } \\
{[\mathrm{W} / \mathrm{m} \cdot \mathrm{K}]}\end{array}$ & S [qualitative] \\
\hline GP_0 & 21.660 & 2.65 & 4.08 & 0.460 & 1832 & 13.00 & 23.0 & 575.000 & 8.00 \\
GP_5 & 18.668 & 2.88 & 3.64 & 0.430 & 1794 & 13.43 & 20.3 & 568.000 & 8.50 \\
GP_10 & 20.826 & 1.92 & 3.23 & 0.340 & 1739 & 13.83 & 15.0 & 521.000 & 9.00 \\
GP_17.5 & 10.633 & 0.59 & 2.58 & 0.270 & 1648 & 16.49 & 10.0 & 470.000 & 9.75 \\
NHL_0 & 14.100 & 2.73 & 2.76 & 0.400 & 1706 & 11.11 & 21.0 & 551.388 & 7.00 \\
NHL_5 & 12.400 & 2.81 & 2.78 & 0.230 & 1474 & 11.54 & 20.0 & 460.518 & 7.50 \\
NHL_10 & 2.850 & 2.82 & 1.53 & 0.082 & 1468 & 18.18 & 18.5 & 292.104 & 8.00 \\
NHL_17.5 & 2.210 & 3.12 & 0.94 & 0.290 & 1581 & 19.49 & 10.0 & 364.031 & 8.75 \\
\hline
\end{tabular}

consensus. This value impacts the alternatives' final ranking, it is set by experts, and generally the value equal to 0.5 is considered (Chatterjee and Chakraborty 2016).

Sorting of the alternatives according to $S_{i}, Q_{i}$ and $R_{i}$ is from the lowest to the highest value. The alternative $\mathrm{a}^{1}$ (i.e., the first alternative in the $R_{i}$ list of the ranking) is a compromise solution if both the following conditions are fulfilled:

(1) Acceptable advantage: where is the alternative ranked second in the Ri ranking list.

(2) Acceptable stability in decision-making: alternative a1 is also the best solution in the Si or/and Qi ranking list.

If just one of the mentioned conditions (1) and (2) is not satisfied, then a set of compromise solutions is given. The set of compromise solutions is determined as follows:

- $a^{l}$ and $a^{2}$ if only the condition (2) is not satisfied

- $a^{l}, a^{2}, \ldots, a^{z}$ if the condition (1) is not satisfied where $a^{z}$ is the last alternative placed in the $R_{i}$ ranking list for which.

\section{Results and discussions}

In this paper the alternatives are the samples reported in Table 2, whereas the evaluation criteria are depicted in Sect. 3.3. The relative importance of the selected criteria was weighed by a board of experts by employing the Delphi technique (Delbecq 1975). The panel of experts was iteratively interviewed asking them to express a judgment of the criteria of relative importance considering the specific application context until an agreement is reached. Considering that the produced samples are intended for architectural finishing with insulating performance, in Table 3 for every evaluation criterion, the preference versus (i.e., if the criterion is to be maximized or minimized) and the weights are reported:

The decision matrix is reported in Table 4. The evaluation of workability criterion is represented through the following trapezoidal membership function:

$f_{i j}=\left\{\begin{array}{cc}\frac{(x-10)}{8} & 10 \leq x<18 \\ 1 & 18 \leq x \leq 22 \\ \frac{(30-x)}{8} & 22<x \leq 30\end{array}\right.$

where $\mathrm{x}$ is the measurement of the workability for every sample obtained by means of the flow table test. With regard to the sustainability criterion, the panel of experts was queried asking them to express a judgment belonging into the interval $[1 ; 10]$ in which 10 is the best value.

Considering the weights and the decision matrix reported in Tables 3 and 4, respectively, the VIKOR method was implemented. The method was applied considering different values of the parameter $v$ starting from 0 to 1 . In particular, $v=1$ emphasizes the strategy of maximum group utility (i.e., majority rule), whereas $v=0$ is the strategy of
Table 5 Values of $R_{i}$ as a function of $v$

\begin{tabular}{llllllll}
\hline Alternatives & $v=0.0$ & $v=0.1$ & $v=0.3$ & $v=0.5$ & $v=0.7$ & $v=0.9$ & $v=1.0$ \\
\hline GP_0 & 0.32012 & 0.32218 & 0.32629 & 0.33041 & 0.33452 & 0.33864 & 0.34069 \\
GP_5 & 0.27862 & 0.27970 & 0.28187 & 0.28404 & 0.28620 & 0.28837 & 0.28945 \\
GP_10 & 0.00000 & 0.00190 & 0.00569 & 0.00948 & 0.01327 & 0.01706 & 0.01896 \\
GP_17.5 & 0.22947 & 0.21811 & 0.19539 & 0.17268 & 0.14996 & 0.12724 & 0.11588 \\
NHL_0 & 1.00000 & 0.95588 & 0.86764 & 0.77940 & 0.69116 & 0.60292 & 0.55880 \\
NHL_5 & 0.57147 & 0.51432 & 0.40003 & 0.28573 & 0.17144 & 0.05715 & 0.00000 \\
NHL_10 & 0.35260 & 0.33467 & 0.29880 & 0.26294 & 0.22707 & 0.19120 & 0.17327 \\
NHL_17.5 & 0.44099 & 0.49689 & 0.60869 & 0.72049 & 0.83230 & 0.94410 & 1.00000 \\
\hline
\end{tabular}


Table 6 Ranking with the VIKOR method as function of $v$

\begin{tabular}{|c|c|c|c|c|c|c|c|c|c|c|c|c|c|}
\hline \# & $\boldsymbol{v}=0.0$ & \# & $\boldsymbol{v}=0.1$ & \# & $\boldsymbol{v}=0.3$ & \# & $v=0.5$ & \# & $\boldsymbol{v}=0.7$ & $\#$ & $v=0.9$ & \# & $v=1.0$ \\
\hline 1 & GP_10 & 1 & GP_10 & 1 & GP_10 & 1 & GP_10 & 1 & GP_10 & 1 & \multirow{3}{*}{$\begin{array}{l}\text { GP_10 } \\
\text { NHL_5 } \\
\text { GP_17.5 }\end{array}$} & \multirow[t]{3}{*}{1} & \multirow{3}{*}{$\begin{array}{l}\text { NHL_5 } \\
\text { GP_10 } \\
\text { GP_17.5 }\end{array}$} \\
\hline 2 & GP_17.5 & 2 & GP_17.5 & 2 & GP_17.5 & 2 & GP 17.5 & & GP_17.5 & & & & \\
\hline 3 & GP_5 & 3 & GP_5 & 3 & GP_5 & 3 & NHL_10 & 2 & NHL_5 & & & & \\
\hline 4 & GP_0 & 4 & GP_0 & 4 & NHL_10 & 4 & GP_5 & 3 & NHL_10 & 2 & NHL_10 & 2 & NHL_10 \\
\hline 5 & NHL_10 & 5 & NHL_10 & 5 & GP_0 & 5 & NHL_5 & 4 & GP_5 & 3 & GP_5 & 3 & GP_5 \\
\hline 6 & NHL_17.5 & 6 & NHL_17.5 & 6 & NHL_5 & 6 & GP_0 & 5 & GP_0 & 4 & GP_0 & 4 & GP_0 \\
\hline 7 & NHL_5 & 7 & NHL_5 & 7 & NHL_17.5 & 7 & NHL_17.5 & 6 & NHL 0 & 5 & NHL_0 & 5 & NHL 0 \\
\hline 8 & NHL_0 & 8 & NHL_0 & 8 & NHL_0 & 8 & NHL 0 & 7 & NHL_17.5 & 6 & NHL_17.5 & 6 & NHL_17.5 \\
\hline
\end{tabular}

minimum individual regret. In Table 5 the values of $R_{i}$ as a function of parameter $v$ are reported:

In correspondence with the values of the parameter $v$ equal to 0.7, 0.9, and 1, the condition (1) reported in Sect. 4 is not satisfied, and therefore a set of compromise solutions will be proposed. The different rankings obtained are reported in Table 6:

A ranking of the samples (Table 7) was also performed by applying the TOPSIS method. As this method is not the core of the paper, the formulas can be found in Sciortino et al. (2019).

It is observed that the sample GP_10 resulted to be in the first position with both the considered multi-criteria methods. Nevertheless, as shown in Table 6, as $v$ increases a set of compromise solutions exists with the VIKOR (i.e., GP_10 and GP_17.5 for $v=0.7$ and NHL_5; GP_10 and GP_17.5 for $v=0.9$ and $v=1$ ). The sample NHL_0 is in the last position with the VIKOR for $v \leq 0.5$, instead for $v>0.5$, and using the TOPSIS approach, the sample NHL_17.5 is placed in last position.

GP_10 indeed shows a good compromise among the various mix designs between engineering performance and SCG implementation. In fact, it is characterized by a very high mechanical resistance in compression (mortar resistance class M20) and an acceptable bending resistance. It is indisputable that all the GP mortars show a higher resistance than NHLs', even though all the produced specimens might be used for applications where the mechanical performance

Table $7 \mathrm{C}^{*}$ values and ranking with the TOPSIS method

\begin{tabular}{ll}
\hline$C^{*}$ & Ranking \\
\hline 0.6270 & GP_10 \\
0.6025 & GP_0 \\
0.5894 & GP_5 \\
0.5785 & NHL_5 \\
0.5283 & NHL_0 \\
0.4742 & NHL_10 \\
0.4580 & GP_17.5 \\
0.2237 & NHL_17.5 \\
\hline
\end{tabular}

plays a greater role, such as in the structural ones. In terms of deformation, GP_10 shows an average deflection and an acceptable strain. Water absorption is not influenced much by the high SCG addition, and the spread on the flow table lets the slurry workable for a suitable mix for finishing application: a suitable workability to be placed onto vertical surfaces. Finally, it shows an implemented thermal insulation making it suitable to improve building energy performance. The great quantity of SCG makes it highly sustainable and innovative in comparison to the virgins and the $5 \%$ mixes, and with better overall performances than $15 \%$ - mainly showing the great limit of being unworkable, and therefore rejected as the main choice.

\section{Conclusions}

In this study a method for evaluating spent coffee grounds potential as an additive within mortar production was investigated to verify if the coffee life cycle can provide an alternative circular process for this coffee biowaste recycling. More particularly, mortars were produced starting from two different binder typologies: a green geopolymer and an ordinary hydraulic lime. SCGs substituted sand in various proportions within the mortar manufacturing. The aggregate mixtures, whose proportions were accurately designed, gave proper features to the analyzed mortars to be qualified for industrial processing. It was observed that some bio-composites showed improved mechanical characteristics. The presence of SCG increases water absorption and improves the insulation performance along with an environmental impact reduction. The considered technological properties are highly promising - such as the improvement in thermal insulating. In particular, even the addition of only 5\% SCG leads to a significant reduction of the thermal conductivity and consequently to a greater insulating performance. Based on the obtained results, it can be stated that spent coffee grounds can be efficiently recycled and employed to produce novel sustainable mortars with suitable mechanical properties and 
low thermal conductivity which could improve the energy efficiency of buildings. Moreover, SCG could be valorized as a secondary raw material avoiding landfill disposal of non-renewable resources. The proposed circular economy solution represents an innovative life cycle-based food waste management which could reduce the costs of mortar manufacturing and the non-renewable natural resource utilization. Complexity, data availability, lack of priority, and cost were identified as major obstacles for mainstreaming life cycle thinking in the economy. Simplifying tools and approaches to model complex systems, as those adopted for the aim of the present study, have the potential to overcome obstacles for mainstreaming life cycle thinking in the economy (Stucki et al. 2021). Among the life cycle-based approaches, most helpful to support decision-makers, multi-criteria decision analysis is particularly appreciated to enhance agri-food waste in the building material field.

Future research developments should concern the analysis of other sets of bio-based materials to evaluate their possible usage in the construction sector, also including further evaluation criteria. In order to make the presented approach a valid decision-making support tool useful for real implementations of CE strategies, a sensitivity analysis could be carried out to check uncertainty levels.

Acknowledgements Manfredi Saeli would like to acknowledge the project PON "Research and Innovation 2014-2020" section 2 "AIM: Attraction and International Mobility" with D.D. 407 of 27/02/2018 co-financed by the European Social Fund - CUP B74I19000650001 id project AIM 1890405-3, area: "Technologies for the Environments of Life", S.C. 08/C1, S.S.D. ICAR/10.

Funding Open access funding provided by Università degli Studi di Palermo within the CRUI-CARE Agreement.

Data Availability The authors declare that the data supporting the findings of this study are available within the article.

Open Access This article is licensed under a Creative Commons Attribution 4.0 International License, which permits use, sharing, adaptation, distribution and reproduction in any medium or format, as long as you give appropriate credit to the original author(s) and the source, provide a link to the Creative Commons licence, and indicate if changes were made. The images or other third party material in this article are included in the article's Creative Commons licence, unless indicated otherwise in a credit line to the material. If material is not included in the article's Creative Commons licence and your intended use is not permitted by statutory regulation or exceeds the permitted use, you will need to obtain permission directly from the copyright holder. To view a copy of this licence, visit http://creativecommons.org/licenses/by/4.0/.

\section{References}

Acevedo F, Rubilar M, Scheuermann E et al (2013) Spent coffee grounds as a renewable source of bioactive compounds. J Biobased Mater Bioenergy 7(3):420-428. https://doi.org/10.1166/ jbmb.2013.1369
ACI 213 (2003) Guide for Structural Lightweight-Aggregate Concrete. Boresi AP, Schmidt RJ, Sidebottom OM (1993) Advanced mechanics of materials. John Wiley and Sons, New York

Chatterjee P, Chakraborty S (2016) A comparative analysis of VIKOR method and its variants. Decis Sci Lett 5:469-486. https://doi.org/ $10.5267 / j . d s 1.2016 .5 .004$

Chu M, Shyu J, Tzeng GH, Khosla R (2004) Comparison among three analytical methods for knowledge communities groupdecision analysis. Expert Syst Appl 33:1011-1024. https://doi. org/10.1016/j.eswa.2006.08.026

Chudley R (2016) Building Construction Handbook. Routledge, London

Crossley OP, Thorpe RB, Peus D, Lee J (2020) Phosphorus recovery from process waste water made by the hydrothermal carbonisation of spent coffee grounds. Bioresour Technol 301:122664. https://doi.org/10.1016/j.biortech.2019.122664

Dattatraya Saratale G, Bhosale R, Shobana S et al (2020) A review on valorization of spent coffee grounds (SCG) towards biopolymers and biocatalysts production. Bioresour Technol 314:123800. https://doi.org/10.1016/j.biortech.2020.123800

de Figueiredo Tavares MP, Mourad AL (2020) Coffee beverage preparation by different methods from an environmental perspective. Int J Life Cycle Assess 25:1356-1367. https://doi.org/10.1007/ s11367-019-01719-2

Delbecq AL, Van de Ven AH, Gustafson DH (1975) Group techniques for program planning: a guide to nominal group and Delphi processes. Scott Foresmann, Glenview

Methods of testing cement - Part 1: Determination of strength European Committee for Standardization Brussels (2016)

Concrete - Part 1: Specification, performance, production and conformity British Standard in European Committee for Standardization Brussels (2006)

EN 998-2 (2016) Specification for mortar for masonry-Part 2: Masonry mortar; European Committee for Standardization, Brussels

EN 1008 (2003) Mixing water for concrete - Specification for sampling, testing and assessing the suitability of water, including water recovered from processes in the concrete industry, as mixing water for concrete. British Standard in European Committee for Standardization, Brussels

EN 1015-3 (1999) Methods of test for mortar for masonry. Determination of consistence of fresh mortar (by flow table). European Committee for Standardization, Brussels

EN 1015-11 (2007) Methods of test for mortar for masonry - part 11: determination of flexural and compressive strength of hardened mortar. European Committee for Standardization, Brussels

Figueroa GA, Homann T, Rawel HM (2016) Coffee production wastes: potentials and perspectives. Austin Food Sci 1(3):1014

Franca AS, Oliveira S (2019) Chapter 17 - Coffee. In: Pan Z, Zhang R, Zicari S (eds) Integrated Processing Technologies for Food and Agricultural By-Products. Academic Press, pp 413-418. https://doi.org/10.1016/B978-0-12-814138-0.00017-4

Getachew AT, Chun BS (2017) Influence of pretreatment and modifiers on subcritical water liquefaction of spent coffee grounds: a green waste valorization approach. J Clean Prod 142:37193727. https://doi.org/10.1016/j.jclepro.2016.10.096

Girotto F, Pivato A, Cossu R, Nkeng GE, Lavagnolo MC (2018) The broad spectrum of possibilities for spent coffee grounds valorization. J Mater Cycles Waste Manage 20(1):695-701. https:// doi.org/10.1007/s10163-017-0621-5

Hwang CL, Yoon K (1981) Multiple Attribute Decision Making: Methods and Applications. Springer-Verlag, Berlin Heidelberg, Berlin

International coffee organization [ICO] (2021) Coffee market report. http://www.ico.org/documents/cy2020-21/cmr-0421-e.pdf

ISO 6946 (2017) Building components and building elements. Thermal resistance and thermal transmittance. Calculation methods. BSI British Standards, London 
Karmee SK (2018) A spent coffee grounds based biorefinery for the production of biofuels, biopolymers, antioxidants and biocomposites. Waste Manage 72:240-254. https://doi.org/10.1016/j. wasman.2017.10.042

Kovalcik A, Obruca S, Marova I (2018) Valorization of spent coffee grounds: A review. Food Bioprod Process 110:104-119. https:// doi.org/10.1016/j.fbp.2018.05.002

Ktori R, Kamaterou P, Zabaniotou A (2018) Spent coffee grounds valorization through pyrolysis for energy and materials production in the concept of circular economy. Mater Today 5:27582-27588. https://doi.org/10.1016/j.matpr.2018.09.078

Kurda R, De Brito J, Silvestre JD (2019) CONCRETop-A multi-criteria decision method for concrete optimization. Environ Impact Assess Rev 74:73-85. https://doi.org/10.1016/j.eiar.2018.10.006

La Fata CM, Giallanza A, Micale R, La Scalia G (2021) Ranking of occupational health and safety risks by a multi-criteria perspective: inclusion of human factors and application of VIKOR. Saf Sci 138:105234. https://doi.org/10.1016/j.ssci.2021.105234

Luz FC, Volpe M, Fiori L, Manni A, Cordiner S, Mulone V, Rocco V (2018) Spent coffee enhanced biomethane potential via an integrated hydrothermal carbonization-anaerobic digestion process. Bioresour Technol 256:102-109. https://doi.org/10.1016/j. biortech.2018.02.021

Massaro Sousa L, Ferreira MC (2019) Spent coffee grounds as a renewable source of energy: an analysis of bulk powder flowability. Particuology 43:92-100. https://doi.org/10.1016/j.partic.2018.06.002

Micale R, Giallanza A, Russo G, La Scalia G (2017) Selection of a Sustainable Functional Pasta Enriched with Opuntia Using ELECTRE III Methodology. Sustainability 9(6):885. https://doi.org/10.3390/ su9060885

Moretti L, Di Mascio P, Bellagamba S (2017) Environmental, Human Health and Socio-Economic Effects of Cement Powders: The Multicriteria Analysis as Decisional Methodology. Int J Environ Res Public Heal 14(6):645. https://doi.org/10.3390/ ijerph14060645

Murthy PS, Naidu MM (2012) Sustainable management of coffee industry by-products and value addition-A review. Resour Conserv Recy 66:45-58. https://doi.org/10.1016/j.resconrec.2012.06.005

Mussatto SI, Machado EMS, Martins S, Teixeira JA (2011) Production, Composition, and Application of Coffee and Its Industrial Residues. Food Bioprocess Technol 4(5):661-672. https://doi. org/10.1007/s11947-011-0565-z

Najdanovic-Visak V, Lee FYL, Tavares MT, Armstrong A (2017) Kinetics of extraction and in situ transesterification of oils from spent coffee grounds. J Environ Chem Eng 5(3):2611-2616. https://doi.org/10.1016/j.jece.2017.04.041

Nguyen HC, Nguyen ML, Wang FM, Liang SH, Bui TL, Ha HH, Su CH (2019) Using switchable solvent as a solvent and catalyst for in situ transesterification of spent coffee grounds for biodiesel synthesis. Bioresour Technol 289:121770. https://doi.org/10.1016/j. biortech.2019.121770

Nortanicola B, Sala S, Anton A, Mc Laren SJ, Saouter E, Sonesson U (2016) The role of life cycle assessment in supporting sustainable agri-food systems: a review of the challenges. J Clean Prod 140:399-409. https://doi.org/10.1016/j.jclepro.2016.06.071

Opricovic S (1998) Multi-criteria Optimization of Civil Engineering Systems. Dissertation, Faculty of Civil Engineering, University of Belgrade

Opricovic S, Tzeng GH (2004) Compromise solution by MCDM methods: A comparative analysis of VIKOR and TOPSIS. Eur J Oper Res 156(2):445-455. https://doi.org/10.1016/S0377-2217(03)00020-1

Opricovic S, Tzeng GH (2007) Extended VIKOR method in comparison with outranking methods. Eur J Oper Res 178(2):514-529. https://doi.org/10.1016/j.ejor.2006.01.020
Peña C, Civit B, Gallego-Schmid A et al (2021) Using life cycle assessment to achieve a circular economy. Int J Life Cycle Assess 26(2):215-220. https://doi.org/10.1007/s11367-020-01856-z

Rangarajan DP (2019) Coffee Waste Management-An Overview. International Journal of Current Research 33(1):9-16

Ronga D, Pane C, Zaccardelli M, Pecchioni N (2016) Use of spent coffee ground compost in peat-based growing media for the production of basil and tomato potting plants. Comm Soil Sci Plant Anal 47(3):356-368. https://doi.org/10.1080/00103624.2015.1122803

Saberian M, Li J, Donnoli A, Bonderenko E, Oliva P, Gill B, Lockrey S, Siddique R (2021) Recycling of spent coffee grounds in construction materials: A review. J Clean Prod 289:125837. https:// doi.org/10.1016/j.jclepro.2021.125837

Saeli M, Novais RM, Seabra MP, Labrincha JA (2017) Mix design and mechanical performance of geopolymer binder for sustainable construction and building material. IOP Conf Ser: Mater Sci Eng 264:012002. https://doi.org/10.1088/1757-899X/264/1/012002

Saeli M, Tobaldi DM, Seabra MP, Labrincha JA (2019a) Mix design and mechanical performance of geopolymeric binders and mortars using biomass fly ash and alkaline effluent from paper-pulp industry. J Clean Prod 208:1188-1197. https://doi.org/10.1016/j. jclepro.2018.10.213

Saeli M, Senff L, Tobaldi DM, La Scalia G, Seabra MP, Labrincha JA (2019b) Innovative Recycling of Lime Slaker Grits from PaperPulp Industry Reused as Aggregate in Ambient Cured Biomass Fly Ash-Based Geopolymers for Sustainable Construction Material. Sustainability 11(12):3481. https://doi.org/10.3390/su11123481

Saeli M, Micale R, Seabra MP, Labrincha JA, La Scalia G (2020) Selection of Novel geopolymeric mortars for sustainable construction applications using fuzzy TOPSIS approach. Sustainability 12:5987. https://doi.org/10.3390/su12155987

San Cristobal JR (2011) Multi-criteria decision-making in the selection of renewable energy project in Spain: The Vikor method. Renew Energy 36:498-502. https://doi.org/10.1016/j.renene. 2010.07.031

Santos C, Fonseca J, Aires A, Coutinho J, Trindade H (2017) Effect of different rates of spent coffee grounds (SCG) on composting process, gaseous emissions and quality of end-product. Waste Manage 59:37-47. https://doi.org/10.1016/j.wasman.2016.10.020

Schmidt Rivera XCS, Gallego-Schmid A, Najdanovic-Visak V, Azapagic A (2020) Life cycle environmental sustainability of valorisation routes for spent coffee grounds: From waste to resources. Resour Conserv Recy 157:104751. https://doi.org/10.1016/j.resconrec. 2020.104751

Sciortino R, Micale R, Saeli M, La Scalia G (2019) Multi criteria evaluation of a sustainable alkali-activated concrete. Proceedings of XXIV Summer School "Francesco Turco" - Industrial Systems Engineering, September 11-13th, 2019, Brescia, Italy, pp 314-320

Son J, Kim B, Park J, Yang J, Lee JW (2018) Wet in situ transesterification of spent coffee grounds with supercritical methanol for the production of biodiesel. Bioresour Technol 259:465-468. https:// doi.org/10.1016/j.biortech.2018.03.067

Stucki M, Jattke M, Berr M, Desing H, Green A, Hellweg S, Laurenti R, Meglin R, Muir K, Pedolin D, Shinde R, Welz T, Keller RL (2021) How life cycle-based science and practice support the transition towards a sustainable economy. Int J Life Cycle Assess 26(5):1062-1069. https://doi.org/10.1007/s11367-021-01894-1

Publisher's Note Springer Nature remains neutral with regard to jurisdictional claims in published maps and institutional affiliations. 


\section{Authors and Affiliations}

\section{Giada La Scalia ${ }^{1}$ (D) Manfredi Saeli ${ }^{2} \cdot$ Pier Paolo Miglietta $^{3} \cdot$ Rosa Micale $^{1}$}

$\triangle$ Giada La Scalia giada.lascalia@unipa.it

1 Department of Engineering, University of Palermo, Viale delle Scienze, Bld 8, Palermo, Italy

2 Department of Architecture, University of Palermo, Viale delle Scienze, Bld 8-14, Palermo, Italy
3 Department of Biological and Environmental Sciences and Technologies, University of Salento, Via per Monteroni, Lecce, Italy 